\title{
O PERFECT EXISTENCIAL E SUAS REALIZAÇÕES MORFOLÓGICAS E ADVERBIAIS NO INGLÊS AMERICANO
}

\author{
Fernanda Costa da Silva Machado ${ }^{1^{\star}}$ \\ Adriana Leitão Martins $\mathbf{s}^{1 *}$ \\ ${ }^{1}$ Universidade Federal do Rio de Janeiro, Rio de Janeiro, RJ, Brasil
}

\begin{abstract}
Resumo
$\mathrm{O}$ aspecto perfect revela um intervalo existente entre dois pontos no tempo. Um dos tipos do perfect é o existencial (PE), que pode estar relacionado a uma situação do passado com efeitos no presente. O objetivo deste estudo é investigar as realizações morfológicas e adverbiais compatíveis com o PE, associado ao tempo presente, no inglês americano (IA). A metodologia consistiu em análises de corpora - entrevistas da TV americana e do Santa Barbara Corpus of Spoken American English - e de dados obtidos por teste linguístico. A hipótese é a de que a realização do PE associado ao tempo presente no IA ocorre só pela perífrase have + particípio, com ou sem apagamento do verbo auxiliar. A hipótese foi refutada, pois o passado simples também foi encontrado veiculando esse aspecto. Discutiu-se sobre a contribuição da forma verbal, dos advérbios de perfect e da pluralidade dos eventos na expressão do $\mathrm{PE}$.

Palavras-chave: Aspecto; Perfect Existencial; Realizações Morfológicas; Realizações Adverbiais; Inglês Americano
\end{abstract}

\section{THE EXISTENTIAL PERFECT AND ITS MORPHOLOGICAL AND ADVERBIAL REALIZATIONS IN AMERICAN ENGLISH}

\begin{abstract}
:
The perfect aspect reveals an interval between two points in time. One of its types is the existential perfect (EP), that may be related to a past situation with effects in the present. The goal of this study is to investigate the morphological and adverbial realizations compatible with the EP, associated with the present, in American English (AE). The methodology consisted of analyses of corpora - interviews taken from the American TV and the Santa Barbara Corpus of Spoken American English - and of
\end{abstract}

\footnotetext{
* Mestranda em Linguística no Programa de Pós-graduação em Linguística da UFRJ. Licenciada em Letras (Português e Inglês) pela UFRJ. Professora de inglês no Ensino Fundamental e Ensino Médio e em cursos de idiomas. E-mail: fernandamachado@letras.ufrj.br. ORCID: http://orcid.org/0000-0002-3951-0652

** Professora Associada de Linguística do Departamento de Linguística e Filologia, do Programa de Pósgraduação em Linguística e do Mestrado Profissional em Letras da UFRJ. E-mail: adrianaleitao@letras.ufrj.br. ORCID: http://orcid.org/0000-0003-0510-2586
} 
data obtained by a linguistic test. The hypothesis is that the realization of the EP associated with the present in AE only occurs through "have" + past participle, with or without the overt realization of the auxiliary verb. The hypothesis was refuted, since the simple past was also found while realizing this aspect. We discussed the contribution of the verbal forms, adverbs and the plurality of events in the expression of the EP.

Keywords: Aspect; Existential Perfect; Morphological Realizations; Adverbial Realizations; American English. 


\section{Introdução $^{1}$}

Neste artigo, assume-se o conceito de aspecto segundo autores tais como Comrie (1976), Dowty (1979), Smith (1997) e Ilari, Oliveira e Basso (2016). Para Comrie (1976), por exemplo, aspecto diz respeito às diferentes maneiras de se enxergar a constituição temporal interna de uma situação, podendo ser classificado como semântico ou gramatical. $\mathrm{O}$ aspecto semântico é relacionado à noção aspectual veiculada através da semântica de itens lexicais. Já o aspecto gramatical se refere à noção aspectual veiculada através, por exemplo, da morfologia verbal. $\mathrm{O}$ valor aspectual, portanto, é dado pela interação de diferentes constituintes sentenciais, $\mathrm{O}$ que é entendido como composicionalidade aspectual (VERKUYL, 1972).

Entende-se ainda que o aspecto gramatical pode ser veiculado através de certos advérbios/expressões adverbiais. Tal entendimento está apoiado em Cinque (1999), que afirma que determinados advérbios/expressões adverbiais desempenham um papel gramatical ou funcional, uma vez que ocupam a posição sintática de especificador de sintagmas alocados na camada funcional da representação estrutural da sentença.

O foco deste trabalho é o aspecto perfect, classificado como um tipo de aspecto gramatical. O perfect diz respeito à informação aspectual utilizada na descrição linguística de uma situação que estabelece uma relação com uma situação anterior, fazendo emergir um intervalo de tempo, e pode ocorrer associado aos tempos passado, presente ou futuro. Neste estudo, investiga-se o perfect associado ao tempo presente.

Uma classificação para o perfect foi apresentada por Iatridou, Anagnostopoulou e Izvorski (2003), na qual o perfect é dividido em universal (PU) ou existencial (PE). Sendo associado ao tempo presente, o PU tem relação com uma situação que se iniciou no passado e persiste até o momento presente, enquanto o PE, que é o foco específico deste trabalho, tem relação com uma situação finalizada no passado, mas que produz efeitos percebidos no momento presente. Exemplos da realização de PU e PE atrelados ao tempo presente no inglês encontram-se a seguir²:

(1) (a) Exemplo de realização de PU associado ao tempo presente Madison has worked in Germany since 2018.

Madison has worked in Germany since 2018

Madison ter.3SG.PRS trabalhar.PTCP PREP Alemanha PREP 2018

'Madison tem trabalhado/trabalha na Alemanha desde 2018.'

(b) Exemplo de realização de PE associado ao tempo presente Madison has been to Paris.

Madison has been to Paris

Madison ter.3SG.PRS estar.PTCP PREP Paris

'Madison (já) esteve em Paris.'

No exemplo (1.a), indica-se uma situação que se iniciou no passado (em 2018) e que continua no momento presente, ou seja, Madison iniciou a ação de "trabalhar na Alemanha” em 2018 e continua trabalhando no mesmo local até hoje. Já 
no exemplo (1.b), existe a indicação no presente de uma experiência vivida por Madison em algum momento de sua vida, o que caracteriza a noção de PE: a situação foi iniciada e finalizada em algum momento no passado, mas seus efeitos são salientes no presente.

Com esse cenário em mente, o objetivo geral deste trabalho é o de contribuir para a descrição das realizações do aspecto perfect nas línguas. Já como objetivo específico, procura-se investigar as realizações morfossintáticas do aspecto $\mathrm{PE}$ associado ao tempo presente no inglês americano. Em outras palavras, busca-se identificar as realizações morfológicas e advérbios/expressões adverbiais compatíveis com a veiculação desse aspecto em particular, associado ao tempo presente, na língua em questão. Para isso, a hipótese formulada é a de que a realização do PE associado ao tempo presente no inglês americano ocorre exclusivamente através da perífrase have + particípio, comumente denominado present perfect ou

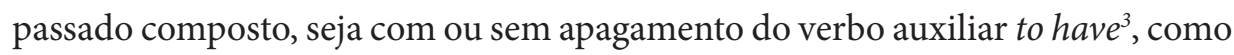
no exemplo (2) a seguir. Tal hipótese foi inspirada em inúmeros estudos nos quais o passado composto é a única morfologia utilizada em exemplificações de sentenças com o aspecto perfect associado ao presente no inglês (COMRIE, 1976; PANCHEVA, 2003; IATRIDOU; ANAGNOSTOPOULOU; IZVORSKI, 2003).

(2) The boy (has) done his homework.

The boy has done his homework

ART menino ter.3SG.PRS fazer.PTCP PRO dever de casa

'O menino (já) fez seu dever de casa.'

O estudo realizado por Lopes (2016) sobre as realizações morfológicas de PU e de PE no inglês britânico, porém, indica que o passado composto não é a única forma verbal possível para se expressar esse aspecto nessa língua. Por exemplo, o PE também pode ser realizado através do passado simples, como no exemplo (3) a seguir, retirado do trabalho da autora citada. O quadro observado de realizações do PE no inglês britânico, portanto, justifica uma investigação sobre outras formas além do passado composto para se expressar esse aspecto na língua inglesa falada em outros locais e em outras línguas.

(3) I broke the window and the glass is cracked.

I broke the window and the glass is

PRO quebrar.PST.PFV ART janela CONJ ART vidro estar.3SG.PRS

cracked

rachar.PTCP

'Eu quebrei a janela e o vidro está rachado.' (LOPES, 2016, p. 118)

Este trabalho está dividido em 4 seções. A primeira seção contém teorias sobre o aspecto perfect, suas realizações e a representação do perfect universal e existencial no sintagma flexional. A segunda seção abarca as etapas metodológicas utilizadas para a investigação do fenômeno em questão. A terceira seção contém os resultados da investigação, devidamente apresentados e discutidos. A quarta e última seção abarca as considerações finais. 


\section{1. $O$ aspecto perfect, suas realizações e sua representação sintática}

Em primeiro lugar, é preciso apresentar a distinção entre tempo e aspecto, categorias linguísticas distintas, mas que podem ser confundidas. De acordo com Comrie (1976), a categoria de tempo possibilita a descrição do momento de uma situação em relação a algum outro momento, geralmente o instante da fala. Já a categoria de aspecto possibilita a descrição da constituição temporal interna de uma situação de diferentes maneiras. Conforme Smith (1997), ainda que apresente uma noção de temporalidade, o conceito de aspecto está conectado a um domínio semântico da estrutura interna das situações. Ainda para essa autora, o fenômeno aspectual é paramétrico, ou seja, pode ser realizado de diferentes maneiras nas línguas naturais.

A categoria gramatical de aspecto, foco deste artigo, tem relação com a noção aspectual que pode ser expressa através da morfologia verbal, por exemplo. O aspecto gramatical é comumente dividido em duas categorias básicas e opostas: o perfectivo e o imperfectivo. De acordo com Comrie (1976), o aspecto perfectivo permite a descrição de uma situação como um todo, sem distinção de seus estágios internos. Já o aspecto imperfectivo possibilita o destaque da estrutura interna da situação, com ênfase nos seus estágios internos.

Ainda segundo Comrie (1976), além das duas categorias básicas de aspecto gramatical, há o aspecto perfect, tema deste trabalho. $\mathrm{O}$ autor indica quatro possíveis classificações para esse aspecto. O perfect de situação persistente relaciona-se com uma situação que começou no passado, mas que continua (ou persiste) no presente. O perfect de resultado, por sua vez, relaciona-se com um estado presente que é o resultado de uma situação no passado. Já o perfect experiencial relacionase com uma situação dada que foi realizada pelo menos uma vez durante algum tempo no passado, com seus efeitos se estendendo até o presente. Finalmente, o perfect de passado recente relaciona-se com uma situação passada que estabelece uma relação com o presente por sua proximidade temporal com este tempo, ou seja, a situação ocorrida no passado é muito recente.

As classificações apresentadas acima para o perfect podem ser conectadas com a classificação apresentada por Iatridou, Anagnostopoulou e Izvorski (2003) em perfect universal (PU) e perfect existencial (PE). Quando associado ao tempo presente, o PU é aquele que indica uma situação passada que persiste no momento presente. Essa definição pode ser vinculada à definição de perfect de situação persistente (COMRIE, 1976), uma vez que ambas as definições fazem menção a uma situação passada não finalizada. No exemplo (4), tem-se uma demonstração da expressão de PU:

(4) Joanna has lived in Paris since 2001.
Joanna has
lived
in Paris since 2001
Joanna ter.3SG.PRS morar.PTCP PREP Paris PREP 2001
'Joanna tem morado/mora em Paris desde 2001.'

No exemplo acima, é possível depreender o conceito do PU, já que Joanna foi morar em Paris em um certo momento do passado, especificamente em 2001, e 
continua morando no mesmo local. Assim, a situação demonstrada na sentença ainda persiste no presente, sem indicação de término.

Já o PE, tema deste trabalho, quando associado ao tempo presente, indica uma situação finalizada no passado que ainda produz efeitos percebidos no presente. Essa definição pode ser vinculada às definições de perfect de resultado, perfect experiencial e perfect de passado recente (COMRIE, 1976), visto que todas expressam a relação entre uma situação finalizada no passado e o momento presente. No exemplo (5), tem-se uma demonstração da expressão de PE:

\section{(5) Joseph has gone to Alabama before. \\ Joseph has gone to Alabama before Joseph ter.3SG.PRS ir.PTCP PREP Alabama ADV 'Joseph (já) foi para o Alabama antes.'}

No exemplo acima, percebe-se o conceito do PE, já que Joseph, em algum momento de sua vida, foi para o Alabama. Essa ação, finalizada no passado, ainda produz efeitos no presente por se tratar de uma experiência vivida pelo sujeito em questão.

Com base nas descrições de Iatridou, Anagnostopoulou e Izvorski (2003), o aspecto perfect se diferencia do perfectivo e imperfectivo porque, ao passo que estes possibilitam que se faça referência exclusivamente ao contorno temporal interno da situação, aquele possibilita que se relacione dois pontos no tempo, com ênfase no intervalo de tempo determinado por esses pontos. Além disso, o perfect ocorre associado aos tempos passado, presente ou futuro e possibilita também a expressão de noções inerentes aos aspectos perfectivo ou imperfectivo, que são, portanto, veiculados junto ao perfect nas sentenças. Neste trabalho, é levado em consideração, para fins de explicação, exemplificação e investigação, apenas o aspecto perfect associado ao tempo presente e como este aspecto é veiculado no inglês americano.

Com base em Cinque (1999), como anunciado na introdução deste artigo, entende-se que o aspecto gramatical pode ser veiculado através de certos advérbios/expressões adverbiais. Iatridou, Anagnostopoulou e Izvorski (2003) argumentam que, apesar de o "present perfect puzzle" indicar a incompatibilidade da forma verbal present perfect com advérbios/expressões adverbiais de tempo definido, como yesterday (ontem), de fato existem advérbios/expressões adverbiais que são compatíveis com tal forma verbal, especificamente no que tange ao conceito de PE, como just (acabar de). Comrie (1976), por sua vez, menciona que os advérbios recently (recentemente) e just podem se conectar à forma verbal do present perfect, especificamente no que se refere ao conceito de perfect de passado recente. Já Fenn (1987) aponta advérbios como already (já) e before (antes) como relacionados ao conceito de perfect experiencial. Pancheva (2003), diferentemente de Comrie (1976), menciona a conexão entre o advérbio just e o conceito de perfect de resultado, bem como indica que o advérbio before está atrelado ao conceito de perfect experiencial. Ressalta-se que as definições de perfect de resultado, experiencial e de passado recente se coadunam com a própria definição de PE. 
Apesar de haver discussões na literatura sobre o fato de perfect ser considerado um tipo de aspecto ou de tempo, assume-se, neste trabalho, a classificação de perfect como aspecto, em conformidade com os estudos de Comrie (1976). Como perfect não é utilizado na descrição puramente de um ponto no tempo, e sim de um intervalo de tempo produzido pela conexão entre dois pontos no tempo, compreende-se que estudos de perfect voltam-se para o exame da constituição temporal interna de uma situação, conceito que se coaduna com a própria definição de aspecto estabelecida por Comrie (1976).

Ainda, em Pancheva (2003), Iatridou, Anagnostopoulou e Izvorski (2003) e Nespoli (2018), dentre outros autores, adota-se a "teoria do agora estendido" como norteadora para o entendimento de perfect como aspecto, já que, nessa teoria, o perfect, quando associado ao presente, é utilizado na descrição de um intervalo de tempo no qual se incluem tanto a situação no passado como a sua conexão com o momento presente. Em versões posteriores da "teoria do agora estendido", também utilizadas pelas autoras citadas, o mesmo intervalo de tempo é denominado de Perfect Time Span (ou PTS), que concentra o intervalo entre o momento do evento e o momento de referência, que pode ser no passado, presente ou futuro.

A partir deste ponto, nos próximos parágrafos, passa-se a discutir como o aspecto perfect é representado na Faculdade da Linguagem (FL), uma vez que, neste artigo, assume-se o pressuposto da modularidade da mente. Assim, é possível entender a linguagem como um módulo único e investigar a FL de maneira independente das demais faculdades. Além disso, entende-se que o aspecto perfect, por possuir um caráter sintático, pode ser explicado a partir da sua representação estrutural na sentença.

Alexiadou, Rathert e Von Stechow (2003) defendem a representação de apenas um nódulo de perfect na árvore sintática. Para tal defesa, as características morfossintáticas da língua inglesa são levadas em consideração. Neste caso, especificamente em relação à morfologia, a forma de passado composto é tida como veiculadora tanto de $\mathrm{PU}$ quanto de $\mathrm{PE}$ nessa língua.

Já Nespoli (2018) e Nespoli e Martins (2018), baseadas em características morfossintáticas de línguas como o português, o italiano, o francês e o espanhol, identificaram morfologias e advérbios/expressões adverbiais distintos para a veiculação de PU e de PE e, com base nisso, sugeriram uma representação do aspecto perfect na árvore sintática, única para todas as línguas naturais, com sintagmas referentes ao PU e ao PE independentes na camada flexional. Logo, ainda que não haja uma realização morfossintática específica para a expressão dos traços alocados nos núcleos desses sintagmas em alguma língua, tais traços estariam invariavelmente presentes na FL e projetariam os sintagmas referidos, sendo, portanto, a representação estrutural de perfect um universal linguístico e as expressões morfossintáticas desse aspecto parametrizadas entre as línguas.

Mais especificamente, Nespoli (2018) propôs que o PU está representado na árvore sintática através do nódulo UPerfP, que abarca o traço [continuativo], e o PE está representado através do nódulo EPerfP, que carrega o traço [resultatividade]. A autora afirmou, ainda, que o nódulo UPerfP dominaria EPerfP na 
hierarquia arbórea. Uma das justificativas plausíveis para essa hierarquia é dada por estudos de aquisição de linguagem. Por exemplo, análises da aquisição do português do Brasil (RODRIGUES, 2019) e do inglês americano (RODRIGUES; MARTINS; NESPOLI, 2019) indicaram que PE é adquirido antes de PU, o que motivaria o posicionamento de EPerfP em um ponto inferior a UPerfP na hierarquia da árvore sintática. Essa assunção é baseada no pressuposto de que os nódulos funcionais mais baixos na arquitetura da sentença são primeiramente adquiridos. Em outras palavras, a aquisição dos nódulos funcionais, indicada pela produção e compreensão das informações gramaticais relacionadas a tais nódulos, se dá "de baixo para cima" em termos da hierarquia da árvore sintática (GUILFOYLE; NOONAN, 1992).

Tendo sido exposta a revisão acerca da representação de perfect, passa-se agora a apresentar uma revisão acerca da realização morfológica desse aspecto na língua inglesa. Retoma-se, por exemplo, o estudo de Lopes (2016), que verificou como o perfect é veiculado no inglês britânico. O resultado dessa pesquisa indicou que o PU é expresso através do passado composto e também da perífrase $b e+$ gerúndio. Já o PE é veiculado através do passado composto e do passado simples, como se pode ver, respectivamente, nos exemplos (6) e (7), retirados de Lopes (2016, p. 62):

(6) (...) for all of the heartwarming positive comments and messages I've received. for all of the heartwarming positive comments and PREP todo PREP ART gentil positivo comentários CONJ messages I have received. mensagens PRO ter.1SG.PRS receber.PTCP

'(...) por todos os comentários e mensagens gentis e positivos que eu recebi.'

(7) I just did it.

I just did it

PRO ADV fazer.PST.PFV PRO

'Eu acabei de fazer isso.'

Como se pode verificar em Lopes (2016), existem duas maneiras diferentes de se veicular o aspecto PE no inglês britânico: o passado composto e o passado simples. Assim, a dúvida sobre como esse aspecto é veiculado no inglês americano tornou-se agente motivador desta pesquisa, uma vez que, como exposto anteriormente, assume-se que as realizações morfossintáticas - por exemplo as de perfect - variam entre as línguas.

Espera-se, com este trabalho, contribuir para a descrição das realizações do aspecto perfect no inglês americano. Para tanto, propõe-se investigar as realizações morfológicas e os advérbios/expressões adverbiais compatíveis com o PE associado ao presente no inglês americano e verificar se há alguma morfologia específica que se associe a um determinado advérbio/expressão adverbial na veiculação desse aspecto.

Apesar de os achados de Lopes (2016) indicarem o uso de passado composto e de passado simples na veiculação de PE no inglês britânico, assumindo que as 
realizações aspectuais variam entre as línguas, e tendo em vista que o passado composto é a única morfologia utilizada para a exemplificação da realização do PE associado ao presente na língua inglesa por autores como Comrie (1976), Iatridou, Anagnostopoulou e Izvorski (2003) e Pancheva (2003), a hipótese formulada para este trabalho é a de que a realização do $\mathrm{PE}$ associado ao tempo presente no inglês americano ocorre exclusivamente através do passado composto, seja com ou sem o apagamento do verbo auxiliar.

Na próxima seção, apresenta-se a metodologia adotada para se testar a hipótese em questão.

\section{Metodologia}

A metodologia desta pesquisa consiste na análise de realizações morfossintáticas do PE associado ao tempo presente no inglês americano por falantes nativos dessa língua. Para tanto, três etapas metodológicas foram utilizadas ${ }^{4}$, configurando-se como fontes de dados distintas: as duas primeiras advindas de análises de corpora e a última advinda de resultados de teste linguístico. A primeira etapa adotada foi a análise de entrevistas de talk shows da TV americana, que foram selecionadas e transcritas. Já a segunda etapa foi a análise de parte do Santa Barbara Corpus of Spoken American English. Finalmente, a terceira e última etapa adotada foi o desenvolvimento e a aplicação de um teste de preenchimento de lacunas. Os detalhes de cada etapa da metodologia são brevemente discutidos a seguir.

$\mathrm{Na}$ primeira etapa metodológica, foram examinadas apenas as ocorrências de PE expressas através do passado composto e as que não continham essa morfologia, mas que continham advérbios/expressões adverbiais que caracterizam esse aspecto, garantindo, assim, sua veiculação ${ }^{5}$. Na exposição dos resultados referentes a essa etapa metodológica, são apresentados as morfologias e os advérbios/ expressões adverbiais utilizados na veiculação de PE encontrados nas entrevistas.

Nessa etapa metodológica, propôs-se a transcrição da fala espontânea em programas televisivos de entrevistas, sendo analisadas um total de nove entrevistas, cada uma com a média de dez minutos de duração. Dois talk shows, ou programas de entrevistas, da TV americana foram considerados: The Tonight Show with Jimmy Fallon e Jimmy Kimmel Live. A opção pela seleção de talk shows em detrimento, por exemplo, de noticiários, foi motivada pelo fato de aqueles refletirem a fala de uma maneira mais espontânea do que a registrada nestes.

Em relação ao perfil dos participantes nesses programas, é importante salientar que tanto os entrevistadores quanto os entrevistados eram falantes adultos nativos do inglês americano. Sobre a faixa de idade dos participantes, os entrevistadores Jimmy Fallon e Jimmy Kimmel, na época das entrevistas, estavam com 42 e 49 anos, respectivamente. Já os entrevistados dos episódios selecionados estavam na faixa de idade entre 34 e 60 anos $^{6}$.

Como é explicitado na seção 3.1, os dados obtidos na primeira etapa metodológica não revelaram a utilização de passado simples na veiculação de $\mathrm{PE}$, o que motivou a inclusão de mais uma etapa metodológica de análise de corpus, 
uma vez que tal resultado poderia ter sido derivado da natureza do primeiro corpus utilizado. Nessa segunda etapa, parte do Santa Barbara Corpus of Spoken American English foi analisada. O corpus, disponível gratuitamente na página eletrônica https://www.linguistics.ucsb.edu/research/santa-barbara-corpus, é baseado em centenas de gravações de fala espontânea de indivíduos americanos, devidamente transcritas, e reflete diferentes situações de fala informal. A escolha por um corpus de produção oral em detrimento de um corpus de produção escrita foi motivada pela maior espontaneidade na oralidade em situações informais, favorecendo a emergência inclusive de formas linguísticas não padrão.

No total, 1 hora e 15 minutos de material foram examinados, divididos entre três eventos de fala, com o total de nove participantes de idade entre 19 e 50 anos. Nesse caso, também foram examinadas apenas as realizações de PE através do passado composto e aquelas que, ainda que contivessem outras morfologias, apresentavam advérbios/expressões adverbiais em contexto de expressão do PE, associado ao tempo presente, no inglês americano.

$\mathrm{Na}$ última etapa metodológica, desenvolveu-se um teste offline escrito de preenchimento de lacunas. Esse teste foi aplicado através de um formulário desenvolvido na plataforma Google Forms. O link para o teste foi disponibilizado através de grupos em redes sociais, como Facebook, e foi respondido por 15 falantes adultos nativos do inglês americano, com idade entre 18 e 45 anos.

No que se refere ao teste, três diálogos foram desenvolvidos com lacunas a serem preenchidas na posição de verbos. No total, seis lacunas-alvo, voltadas especificamente para a eliciação de PE, e 12 lacunas distratoras foram implementadas no teste, sendo duas lacunas-alvo e quatro lacunas distratoras em cada um dos diálogos. Um contexto de informalidade foi desenvolvido para cada um dos diálogos, para que a naturalidade da fala fosse expressa de maneira efetiva na escrita. Por conta disso, os diálogos tiveram como temática situações do dia a dia, como festa de aniversário e ida ao supermercado.

Todas as lacunas, alvo ou distratoras, deveriam ser completadas com formas flexionadas de verbos indicados no infinitivo entre parênteses ao lado de cada lacuna apresentada. Destaca-se que todos os verbos selecionados para as lacunas -alvo tinham formas diferentes de passado simples e de particípio, de modo que o preenchimento da lacuna poderia garantir se o participante estava produzindo, naquele caso, o passado simples ou o passado composto com o apagamento do verbo auxiliar. Inclusive, a motivação para a elaboração de uma terceira etapa metodológica tem relação com a necessidade de se controlar essa questão, possibilitando uma análise precisa da forma verbal produzida, o que às vezes não era possível na análise da fala espontânea nas duas primeiras etapas metodológicas pelo fato de o verbo utilizado poder apresentar a mesma forma no passado simples e no particípio.

Nas lacunas-alvo, o PE poderia ser elicitado de duas formas: pelo contexto do diálogo ou pelo contexto e pelos advérbios característicos de PE utilizados na sentença com a lacuna-alvo. Em metade das sentenças com lacunas-alvo, o PE era elicitado apenas pelo contexto. De acordo com Molsing (2010), o PE pode 
ocorrer sem que esteja acompanhado da realização fonética de um advérbio/expressão adverbial veiculador de perfect. Assim, acredita-se que, ainda que o advérbio/expressão adverbial não estivesse foneticamente realizado nas sentenças que continham essas lacunas-alvo, ele estaria sintaticamente ativo (NESPOLI e MARTINS, 2018) e poderia ser recuperado através do próprio contexto apresentado no diálogo, por meio da explicitação, na história, que a situação referida na lacuna-alvo tinha se dado no passado e tinha uma relação explícita com o presente, caracterizando assim o intervalo PTS necessário à veiculação de PE.

Já na outra metade das sentenças com lacunas-alvo, o PE era elicitado não só pelo contexto, mas também por um advérbio utilizado na sentença em que havia a lacuna-alvo, a saber, advérbios recently, nas lacunas relacionadas aos verbos to take (fazer) e to throw (dar; preparar), ou before, na lacuna relacionada ao verbo to see (ver) ${ }^{7}$. A escolha de tais advérbios justifica-se pelo fato de serem considerados advérbios veiculadores de perfect segundo Comrie (1976), Fenn (1987) e Pancheva (2003), conforme descrito na seção 1.

Vale destacar ainda que, nas lacunas-alvo do teste, produções contendo o passado simples possibilitariam a refutação da hipótese desta pesquisa, enquanto produções contendo o passado composto, com ou sem apagamento do verbo auxiliar, não possibilitariam tal refutação.

Antes do início efetivo do teste, o participante era apresentado a algumas instruções acerca das tarefas e de seu objetivo, tais como as informações de que ele seria apresentado a três diálogos com lacunas a serem preenchidas com o verbo dado na forma infinitiva entre parênteses, utilizando-o da maneira que julgasse mais natural e acrescentando ainda outras palavras, se assim desejasse. Pedia-se, ainda, que o participante utilizasse sua intuição enquanto falante nativo da língua, não havendo respostas corretas ou incorretas. Além disso, o participante era informado de que poderia deixar de participar a qualquer momento da pesquisa, que sua participação não seria remunerada e que os dados seriam sinteticamente apresentados, não possibilitando a revelação de sua identidade. Logo, essa seção inicial do teste buscava trazer transparência na explicitação da pesquisa, garantindo a ética necessária ao fazer científico.

Exemplos de lacuna-alvo e de lacuna distratora podem ser verificados abaixo:

(8) Lacuna-alvo

(...) I___ (to see) so many cute and stupid guys before (...)

(...) I___ (to see) so many cute and stupid guys before (...)

PRO _ _ (ver) muito muito bonito CONJ estúpido rapazes ADV

'(...) Eu (já) ___ (ver) tantos rapazes bonitos e estúpidos antes (...)'

(9) Lacuna distratora

(...) if I have a chance of ______ (to become) a pro.

(...) if I have a chance of (to become) a CONJ PRO ter.1SG.PRS ART chance PREP_____(virar) ART

pro.

profissional

‘(...) se eu tenho uma chance de (virar) um profissional.' 
Na próxima seção, são explicitados os resultados obtidos nas três etapas metodológicas descritas nesta seção.

\section{Resultados e discussão}

Nesta seção, são apresentados, em subseções distintas, os resultados obtidos por meio da coleta de dados em cada uma das três etapas metodológicas descritas na seção anterior. Ressalta-se que as ocorrências de advérbios/expressões adverbiais também são apresentadas em uma subseção à parte. Por fim, a última subseção destina-se à discussão dos resultados apresentados nas demais.

\subsection{As realizações morfológicas obtidas na primeira etapa metodológica}

Foram contabilizadas 11 ocorrências de PE associado ao tempo presente através da análise das entrevistas. Dentre essas ocorrências, cinco ocorrências foram expressas pelo passado composto, três ocorrências foram expressas pelo passado composto com apagamento do verbo auxiliar e três ocorrências foram expressas por uma forma morfologicamente ambígua, que poderia ser classificada como passado simples ou passado composto com apagamento do verbo auxiliar, já que as formas do passado simples e do particípio dos verbos em questão eram iguais. O gráfico abaixo representa sinteticamente os dados obtidos através da análise de entrevistas:

Gráfico 1: Formas verbais que expressam PE nas entrevistas retiradas da TV americana
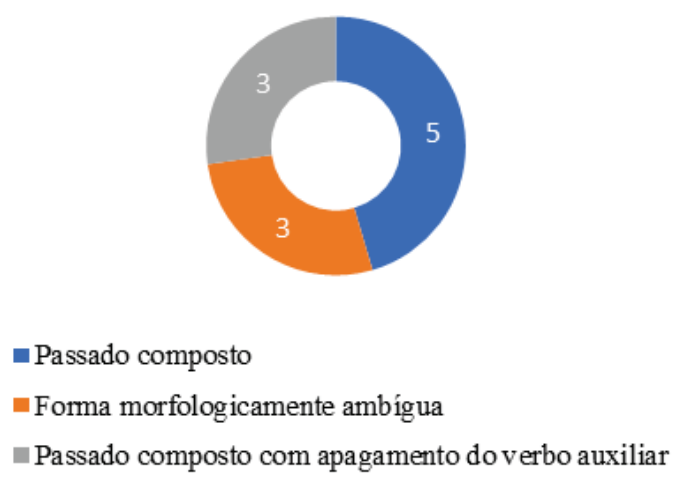

Fonte: elaboração própria

Abaixo, seguem exemplos de ocorrências com cada uma das formas verbais encontradas que expressam PE associado ao tempo presente no inglês americano. As formas verbais encontram-se em negrito: 
(10) (a) Passado composto

Well, this one (vacation) was really good, but we've had some bad ones.

Well this one vacation was really good but we

bom PRO um férias ser.3SG.PST.PFV muito bom CONJ PRO

have had some bad ones

ter.1PL.PRS ter.PTCP algum ruim uns

'Bom, essas (férias) foram muito boas, mas nós (já) tivemos algumas ruins.'

(b) Passado composto com apagamento do verbo auxiliar

I broken actually tons (of bones).

I broken actually tons of bones

PRO quebrar.PTCP na verdade vários PREP ossos

'Eu, na verdade, (já) quebrei vários (ossos).'

(c) Forma morfologicamente ambígua

We finally just moved out.

We finally just moved out

PRO finalmente ADV mudar-se(?)

'Nós finalmente nos mudamos.'

Destaca-se aqui o exemplo (9c) para análise, uma vez que foi caracterizado como uma forma morfologicamente ambígua. O verbo em negrito, sendo regular, possui a mesma forma de passado simples e de particípio, que é utilizada na formação do passado composto. Ou seja, no momento da análise desse tipo de dado, não foi possível indicar que forma, de fato, era essa: o passado composto com apagamento do verbo auxiliar ou o passado simples. Assim, as outras etapas metodológicas deste estudo se fizeram necessárias.

\subsection{As realizações morfológicas obtidas na segunda etapa metodológica}

Foram contabilizadas nove ocorrências de $\mathrm{PE}$ associado ao tempo presente através da análise de um recorte do Santa Barbara Corpus of American Spoken English. Dentre essas ocorrências, quatro ocorrências foram expressas pela mesma forma morfologicamente ambígua descrita em 3.1, três ocorrências foram expressas pelo passado composto e duas ocorrências foram expressas pelo passado simples. O gráfico abaixo representa sinteticamente os dados encontrados durante a análise do Santa Barbara Corpus of American Spoken English: 
Gráfico 2: Formas verbais que expressam PE no Santa Barbara Corpus of American Spoken English

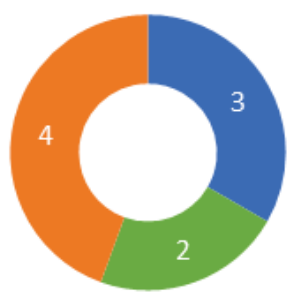

- Passado composto $\quad$ Passado simples $\quad$ Forma morfologicamente ambígua

Fonte: elaboração própria

Abaixo, seguem exemplos de ocorrências com cada uma das formas verbais encontradas que expressam PE associado ao tempo presente no inglês americano. As formas verbais encontram-se em negrito:

(11) (a) Forma morfologicamente ambígua

I just read an article on him.

I just read an article on him

PRO ADV ler(?) $)^{9}$ ART artigo PREP PRO

'Eu acabei de ler um artigo sobre ele.'

(b) Passado compost

Dad, you know, has done some of it.

Dad you know has done some of papai PRO saber.2SG.PRS ter.3SG.PRS fazer.PTCP algum PREP

it

PRO

'Papai, sabe, fez parte disso'.

(c) Passado simples

I went there before, it was fine.

I went there before it was fine

PRO ir.PST.PFV ADV ADV PRO ser.3SG.PST.PFV bom

'Eu fui lá antes, foi bom.'

Na próxima subseção, os resultados obtidos na etapa metodológica relacionada ao experimento linguístico são descritos.

\subsection{As realizações morfológicas obtidas na terceira etapa metodológica}

Para a apresentação dos resultados dessa etapa metodológica, são descritas as formas verbais obtidas em cada uma das lacunas-alvo separadamente. Para tanto, faz-se menção a cada um dos diálogos desenvolvidos, que continham duas lacunas-alvo cada. 
Em relação às ocorrências obtidas na primeira lacuna-alvo do diálogo 1 do experimento linguístico, na qual o verbo to come (passar) era requisitado para o preenchimento da lacuna, 14 ocorrências foram de passado simples e uma ocorrência foi de um verbo diferente do indicado entre parênteses imediatamente após a lacuna em questão. Portanto, esse dado foi excluído da análise, já que os verbos indicados para o preenchimento das lacunas-alvo foram devidamente selecionados para que se evitasse o uso de formas morfologicamente ambíguas por parte dos participantes. Assim, apenas verbos irregulares que possuíssem formas de passado simples e de particípio diferentes foram escolhidos ${ }^{10}$. Já na segunda lacuna-alvo do mesmo diálogo, com a indicação de uso do verbo to take, obtiveram-se 15 ocorrências de passado simples para expressar o aspecto estudado, ou seja, todos os participantes, neste caso, utilizaram a mesma forma para preencher a lacuna.

Já em relação às ocorrências obtidas na primeira lacuna-alvo do diálogo 2, com a indicação de uso do verbo to go (ir), 15 ocorrências foram de passado simples. Na segunda lacuna-alvo do mesmo diálogo, com a indicação de uso do verbo to throw, 12 ocorrências foram de passado simples, uma ocorrência foi de passado composto e duas ocorrências foram de verbos diferentes do indicado entre parênteses. Estes últimos dados, portanto, foram descartados da análise conforme a justificativa descrita no parágrafo anterior.

Finalmente, em relação às ocorrências obtidas na primeira lacuna-alvo do diálogo 3, com a indicação de uso do verbo to undergo (passar por), 12 ocorrências foram de passado simples, duas ocorrências foram de passado composto e uma ocorrência foi de um verbo diferente do indicado entre parênteses, sendo este último dado excluído da análise. Na segunda lacuna-alvo do mesmo diálogo, com a indicação de uso do verbo to see, obtiveram-se oito ocorrências de passado simples, cinco ocorrências de passado composto e duas ocorrências de um verbo não solicitado e devidamente excluído. O gráfico abaixo representa sinteticamente os dados encontrados durante a análise dos resultados do experimento linguístico:

Gráfico 3: Formas verbais utilizadas para completar as lacunas-alvo do experimento linguístico ${ }^{11}$

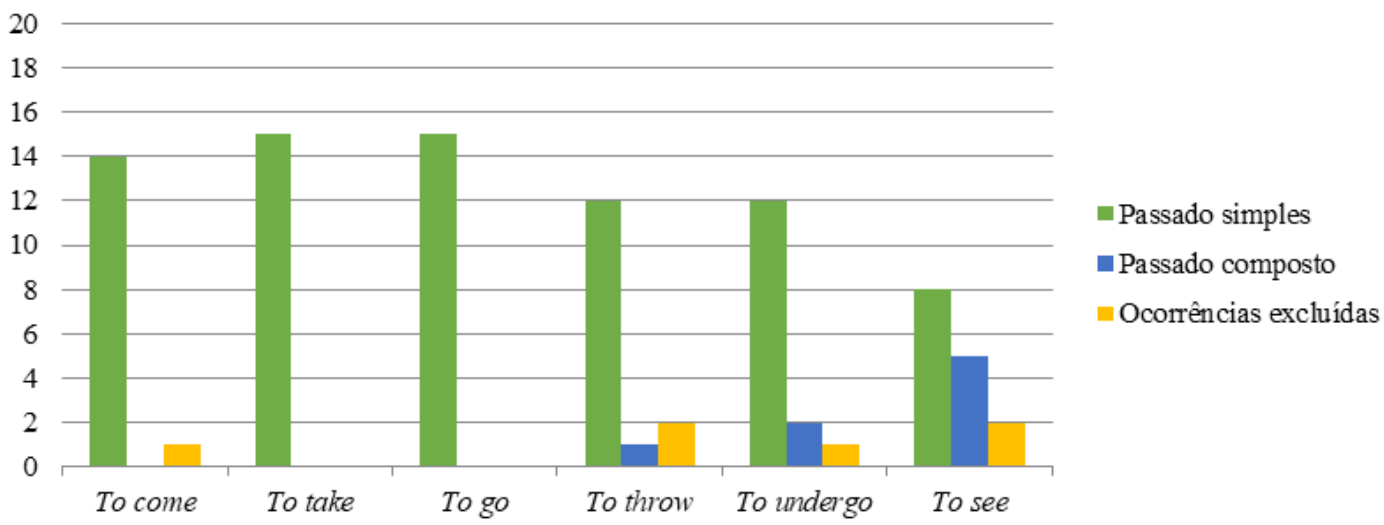

Fonte: elaboração própria 
Na próxima subseção, os advérbios/expressões adverbiais veiculadores de perfect encontrados nas duas primeiras etapas metodológicas são explicitados.

\subsection{Os advérbios/expressões adverbiais identificados nas etapas metodológicas}

A análise dos advérbios/expressões adverbiais utilizados na veiculação de $\mathrm{PE}$ associado ao tempo presente no inglês americano também faz parte dos objetivos deste trabalho. Assim, as ocorrências de advérbios/expressões adverbiais, relacionadas às formas verbais encontradas nas sentenças em que havia veiculação de $\mathrm{PE}$, são indicadas nos gráficos desta seção. As formas verbais encontradas, conforme descrito nas três subseções anteriores, foram: passado simples, passado composto (sem e com apagamento do verbo auxiliar) e forma morfologicamente ambígua.

No teste linguístico, as lacunas figuravam na posição do verbo e, embora os participantes pudessem acrescentar outros itens além do verbo, nenhum deles acrescentou algum advérbio/expressão adverbial nas lacunas-alvo sem tal advérbio já estar presente na sentença. É importante reforçar que, para elicitar a produção de PE na metade das sentenças em que figuravam as lacunas-alvo, foram utilizados os advérbios recently e before. Destaca-se que as sentenças nas quais os verbos to take, to throw e to see eram requisitados para o preenchimento das lacunas-alvo eram aquelas em que ocorriam os advérbios recently (lacunas-alvo com os verbos to take e to throw) e before (lacuna-alvo com o verbo to see). No entanto, como pode ser verificado no gráfico 3 exposto na subseção anterior, a incidência de passado simples foi bem mais expressiva mesmo nessas lacunas-alvo.

Por ter-se optado pela utilização de advérbios específicos no teste linguístico, indicam-se por meio de gráficos desta subseção apenas advérbios/expressões adverbiais encontrados nas análises de corpora das duas primeiras etapas metodológicas. Ainda assim, os advérbios utilizados no experimento são abordados quando da discussão dos resultados, bem como a relação entre os advérbios utilizados no experimento e a forma verbal empregada pelos participantes.

Nas entrevistas, apenas a forma morfologicamente ambígua apareceu acompanhada de advérbios que auxiliaram na expressão do aspecto estudado. Do total de três sentenças com a forma morfologicamente ambígua, duas vinham acompanhadas de just e uma, de before. O gráfico abaixo representa sinteticamente os advérbios encontrados na análise dos dados das entrevistas: 
Gráfico 4: Advérbios/expressões adverbiais e formas verbais utilizadas nas entrevistas

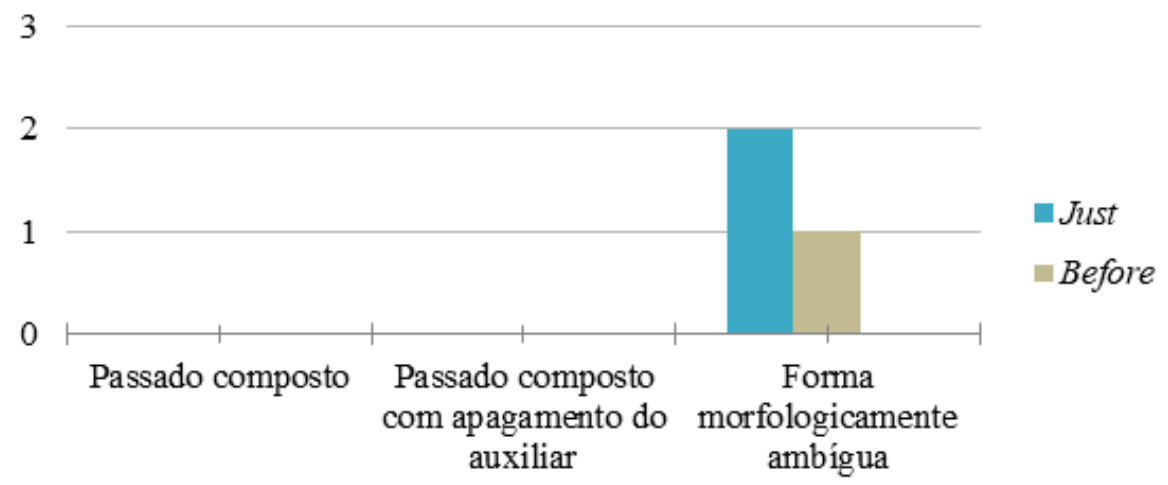

Fonte: elaboração própria

De acordo com os dados obtidos através do Santa Barbara Corpus of American Spoken English, todas as formas verbais veiculadoras de PE encontradas vieram acompanhadas, pelo menos uma vez, de advérbios que auxiliaram na expressão do aspecto estudado, a saber: just, before e already. De um total de nove sentenças veiculadoras do aspecto estudado, as duas sentenças com passado simples foram acompanhadas de before, duas sentenças com passado composto (das três sentenças com essa forma verbal) foram acompanhadas de just e already, respectivamente, e as quatro sentenças encontradas com a forma morfologicamente ambígua foram acompanhadas de just. O gráfico abaixo representa sinteticamente os advérbios encontrados na análise dos dados do Santa Barbara Corpus of American Spoken English:

Gráfico 5: Advérbios/expressões adverbiais e formas verbais utilizadas no Santa Barbara Corpus of American Spoken English

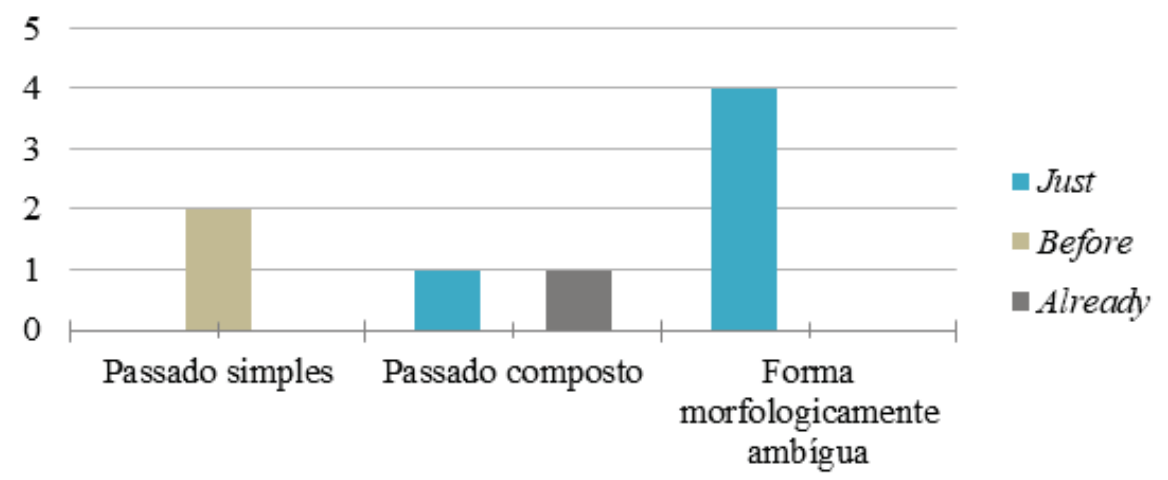

Fonte: elaboração própria

Na próxima subseção, os resultados descritos até este ponto da seção 3 são discutidos. 


\subsection{Discussão dos resultados}

Com base nos resultados apresentados até aqui, pode-se chegar a conclusões em relação às realizações morfossintáticas do $\mathrm{PE}$ associado ao tempo presente no inglês americano. Resumindo os resultados encontrados nas três etapas metodológicas, encontraram-se as seguintes formas verbais veiculadoras do aspecto em questão: passado composto (sem e com apagamento do verbo auxiliar) e passado simples. Entende-se, portanto, que essas formas verbais estão igualmente a serviço da expressão sintático-semântica de uma situação finalizada no passado que produz um resultado saliente no presente. Com base apenas nos resultados das duas primeiras etapas metodológicas, encontrou-se ainda uma forma que poderia ser classificada como passado composto com apagamento do verbo auxiliar ou passado simples, por possuir um verbo cuja morfologia era a mesma no particípio e no passado simples, tendo por isso sido classificada como "forma morfologicamente ambígua".

Tentou-se dirimir a dúvida sobre a forma morfologicamente ambígua através do teste de preenchimento de lacunas, no qual se utilizaram apenas formas verbais irregulares com diferenças morfológicas entre passado simples e particípio, de modo que não poderiam emergir tais formas ambíguas. Desse modo, no teste, observou-se a preferência pelo uso de passado simples na veiculação de PE associado ao presente no inglês americano.

Dessa forma, a hipótese de que a realização do PE associado ao tempo presente no inglês americano ocorre exclusivamente através do passado composto, seja com ou sem apagamento do verbo auxiliar, foi refutada, uma vez que tal forma verbal não foi a única utilizada pelos sujeitos na expressão desse aspecto nos dados obtidos neste estudo. Além do passado composto, forma mais amplamente utilizada na exemplificação de sentenças veiculadoras de perfect na literatura, como exposto ao final da seção 1 deste artigo, o passado simples foi encontrado em contexto de veiculação de PE associado ao tempo presente no inglês americano, tal como já havia sido observado no inglês britânico por Lopes (2016). É importante ressaltar que o passado simples foi analisado enquanto veiculador de perfect na análise de corpus apenas se houvesse a utilização dessa forma verbal em sentenças com advérbios descritos como veiculadores de perfect pelos autores Comrie (1976), Fenn (1987) e Pancheva (2003).

Vale destacar que, neste estudo, também se sustenta que o passado composto, ainda que não seja a morfologia preferida para a expressão de PE, garante a especificação positiva do traço sintático que projeta o sintagma de $\mathrm{PE}$ e, por isso, é tão amplamente utilizado na exemplificação desse aspecto na literatura (COMRIE, 1976; IATRIDOU; ANAGNOSTOPOULOU; IZVORSKI, 2003; PANCHEVA, 2003). Por conta disso, a utilização dessa morfologia parece inclusive dispensar a realização fonética de advérbios/expressões adverbiais de perfect, que, neste caso, estariam apenas sintaticamente ativos (MOLSING, 2010; NESPOLI; MARTINS, 2018). Tal argumentação sustenta-se no fato de que a totalidade das sentenças das entrevistas e uma das sentenças do Santa Barbara Corpus of American Spoken 
English com a forma de passado composto ocorreu sem a presença de advérbios/ expressões adverbiais relacionados ao aspecto estudado.

A análise dos advérbios/expressões adverbiais de perfect associados às formas verbais presentes nos dados deste estudo permite que se faça algumas considerações. Primeiramente, com base na análise dos dados do corpus da segunda etapa metodológica, identificou-se que uma sentença com o passado composto e quatro sentenças com a forma morfologicamente ambígua ocorreram junto de just, o qual indica que uma ação acabou de ocorrer. Na sentença em que o passado composto aparece associado ao advérbio just (em "they [the horses] just haven't been disciplined enough"), a expressão de uma sequência de eventos é revelada. Já em todas as sentenças nas quais a forma morfologicamente ambígua ocorreu junto do advérbio em questão (como em "I just read an article on him ${ }^{12}$ "), a expressão de um evento único pode ser depreendida. Assim, discute-se que o advérbio just - ainda que seja descrito como advérbio veiculador de perfect -, quando associado à forma morfologicamente ambígua para a descrição de eventos passados no singular, não expresse PE e sim apenas perfectivo. Por isso, a forma morfologicamente ambígua, nestes casos, talvez devesse ser interpretada como passado simples veiculando exclusivamente perfectivo.

Em segundo lugar, ainda com base na análise dos dados do corpus da segunda etapa metodológica, constatou-se também que as duas ocorrências de passado simples deram-se junto de before, advérbio caracterizado como veiculador de perfect que faz categoricamente emergir um intervalo de tempo entre duas situações, o que se conecta à definição basilar de perfect. Logo, sustenta-se que, nestes casos, há garantia do uso de passado simples veiculando PE, o que, como já argumentado antes, garante a refutação da hipótese desta pesquisa.

Em terceiro lugar, sobre a relação entre os advérbios/expressões adverbiais de perfect e as formas verbais utilizadas a partir dos resultados obtidos no experimento, concluiu-se que: mesmo nas sentenças sem advérbios/expressões adverbiais de perfect foneticamente realizados, a maioria dos participantes optou pelo uso do passado simples para a veiculação do aspecto em questão. E é importante ressaltar que as sentenças nas quais figuravam as lacunas-alvo foram produzidas para o experimento de tal forma que a veiculação de PE estivesse garantida, já que havia um contexto criado pelo diálogo que forçava a interpretação de que, naquela sentença, descrevia-se uma situação passada que estabelecia relação com o presente, ou seja, um intervalo PTS emergia da descrição daquela situação. Portanto, a forma de passado simples utilizada pelos participantes no teste linguístico para preencher essas lacunas não poderia ser caracterizada como puramente veiculadora de perfectivo, mas sim de perfectivo em combinação com PE, reforçando que o passado simples é uma forma verbal possível para a realização de PE.

Em quarto lugar, cabe destacar uma questão concernente ao advérbio recently, utilizado para acompanhar duas lacunas-alvo no experimento, as quais deveriam ser completadas com os verbos to throw e to take. Ambas as lacunas-alvo figuravam em sentenças que buscavam expressar um evento único ocorrido no passado, e não uma sequência de eventos. No caso da lacuna-alvo com o verbo 
to throw, a ideia expressa era de to throw a party (dar; preparar uma festa). Já na lacuna-alvo com to take, a ideia expressa era de to take a writing course (fazer um curso de escrita). Ainda que Molsing (2010) afirme que a estrutura de passado composto no inglês possa expressar tanto eventos singulares (como em "John has arrived late once"), quanto eventos que são repetidos (como em "John has arrived late three times ${ }^{13}$ "), o fato de eventos singulares terem sido evocados nas sentenças das lacunas-alvo acompanhadas do advérbio recently pode ter favorecido o maior uso do passado simples pelos participantes do experimento nessas duas lacunas-alvo em específico. Especula-se, pois, que a expressão de um evento único associado ao advérbio recently possa ter levado à interpretação de uma situação finalizada no passado sem conexão com o presente, o que vai na direção da interpretação dada para o uso do advérbio just associado à forma morfologicamente ambígua encontrada na segunda etapa metodológica. Em outras palavras, supõese que, se nas sentenças das lacunas-alvo nas quais figurava o advérbio recently houvesse a expressão de uma sequência de eventos que aconteceram em um passado recente, talvez a forma de passado composto pudesse ter sido mais utilizada pelos participantes ${ }^{14}$.

Desse modo, discute-se que a análise do $\mathrm{PE}$ associado ao tempo presente deve passar, necessariamente, pela observação das formas verbais, pela análise dos advérbios/expressões adverbiais e pelo exame dos eventos retratados enquanto singulares ou plurais, para que se entenda se realmente o aspecto em questão está sendo, de fato, expresso. Quanto às formas verbais, destaca-se que este estudo demonstra que tanto o passado composto (sem e com apagamento do auxiliar) quanto o presente simples podem veicular o aspecto PE no inglês americano. Quanto aos advérbios/expressões adverbiais, ressalta-se que existe a possibilidade de que advérbios/expressões adverbiais de PE não sejam foneticamente realizados na sentença (MOLSING, 2010), mas sejam retomados a partir do contexto descrito, evidenciando que eles estão sintaticamente ativos (NESPOLI; MARTINS, 2018), de modo que é possível a veiculação de PE em uma sentença até mesmo com o passado simples e a não realização fonética do advérbio/ expressão adverbial. Finalmente, quanto ao evento retratado ser singular ou plural, retoma-se que, possivelmente, sentenças com advérbios caracterizados como veiculadores de perfect, como just e recently, talvez só efetivamente veiculem PE em sentenças com o passado simples se o evento retratado for plural, como em "John threw parties at home recently $y^{15 "}$.

Reforça-se aqui que a forma verbal de passado simples foi a mais produtiva nos dados obtidos pelo teste linguístico para a realização de PE associado ao presente no inglês americano. A esse respeito, vale destacar que o inglês americano parece seguir a mesma tendência encontrada em línguas românicas revelada na pesquisa de Nespoli (2018), na qual são identificadas formas verbais distintas para expressar PU e PE nas línguas investigadas, o que levou a autora a defender a proposição de sintagmas distintos na estrutura arbórea da sentença para cada um desses tipos de perfect. No caso do inglês americano, Jesus (2016) indica que o PU é realizado de maneira produtiva pelo passado composto, pela forma ver- 
bal formada por be + gerúndio e pelo presente simples, enquanto o PE, como indicado também neste trabalho, é realizado de maneira produtiva pela forma de passado simples, sendo o passado composto utilizado em menor escala para esse fim. Assim, na mesma linha de argumentação adotada por Nespoli (2018), sustenta-se que os dados apresentados neste estudo em confronto com aqueles apresentados em Jesus (2016) são compatíveis com a proposta de que PE e PU, por serem realizados de maneiras morfossintaticamente distintas, caracterizam tipos distintos de perfect que projetam sintagmas independentes na estrutura arbórea da sentença.

\section{Considerações finais}

Neste trabalho, investigou-se como o aspecto PE associado ao tempo presente é realizado no inglês americano. Neste caso, foram estudadas formas verbais e advérbios/expressões adverbiais que veiculavam o aspecto em questão. Para que tal objetivo fosse alcançado, três etapas metodológicas foram adotadas: entrevistas retiradas da TV americana foram transcritas e analisadas, um recorte do Santa Barbara Corpus of Spoken American English foi analisado e um teste de preenchimento de lacunas foi desenvolvido e aplicado a falantes nativos do inglês americano. A terceira etapa garantiu que o passado simples é uma forma verbal também bastante produzida para a veiculação do aspecto em questão.

Assim, concluiu-se que o PE associado ao tempo presente é realizado no inglês americano através das seguintes formas: (i) passado composto (sem e com apagamento do verbo auxiliar) e (ii) passado simples. A hipótese deste trabalho de que a realização do PE associado ao tempo presente no inglês americano ocorre exclusivamente através do passado composto, havendo ou não o apagamento do verbo auxiliar, foi refutada, já que, pela análise dos resultados das segunda e terceira etapas metodológicas, constataram-se dados de realização do PE através do passado simples.

Concluiu-se ainda que, como é amplamente sustentado na literatura sobre aspecto como um todo (VERKUYL, 1972; COMRIE, 1976; SMITH, 1997), não é possível estudar o perfect apenas do ponto de vista de uma análise morfológica, na direção do que é também defendido por Nespoli (2018). O estudo dos advérbios/ expressões adverbiais veiculadores de PE e o exame da singularidade/pluralidade dos eventos ampliam o entendimento das realizações do aspecto em questão.

Finalmente, esta pesquisa contribuiu para as discussões teóricas sobre as realizações do PE associado ao tempo presente no inglês americano, pois houve a indicação de que o passado simples possa ser a forma preferida para a veiculação de PE, apesar do que é visto na literatura sobre o tema, já que, neste caso, o passado composto é a forma mais amplamente utilizada na exemplificação de sentenças veiculadoras de perfect. Além disso, colaborou-se para a descrição de advérbios/expressões adverbiais associados ao PE. Portanto, o objetivo geral desta pesquisa foi alcançado, pois pôde-se auxiliar na descrição das realizações do aspecto perfect nas línguas. 


\section{Notas}

1. Este artigo é derivado da monografia produzida por Fernanda Costa da Silva Machado, sob a orientação de Adriana Leitão Martins, na qual se analisaram as realizações morfossintáticas do perfect existencial associado ao tempo presente no inglês americano. Uma nativa do inglês americano foi consultada durante o desenvolvimento do trabalho, uma vez que as autoras possuem o português brasileiro como língua materna.

2. Ao longo do artigo, utilizou-se uma glosa cujas abreviações devem ser assim entendidas: (i) 1SG, 2SG, 3SG, 1PL, 2PL, 3PL como, respectivamente, primeira, segunda e terceira pessoas do singular e primeira, segunda e terceira pessoas do plural, (ii) PRS como presente, (iii) PST como passado, (iv) PFV como perfectivo, (v) PTCP como particípio, (vi) PRO como pronome, (vii) ART como artigo, (viii) PREP como preposição, (ix) ADV como advérbio e (x) CONJ como conjunção.

3. Toma-se aqui o "apagamento do verbo auxiliar" como a não realização fonética desse item, podendo ser entendido, portanto, como o apagamento de parte da realização morfológica do chamado "passado composto".

4. Como é explicitado ao longo desta seção, as etapas metodológicas selecionadas para a pesquisa possibilitaram a obtenção de dados de produção de falantes nativos do inglês americano. Uma etapa posterior deste estudo pode também incluir a adoção de testes de julgamento de gramaticalidade, por exemplo. Contudo, entende-se que apenas os dados positivos coletados através das etapas metodológicas adotadas são suficientes para a argumentação empreendida neste estudo.

5. Os advérbios que caracterizam o PE considerados nesta pesquisa são aqueles ilustrados por Comrie (1976), Fenn (1987), Iatridou, Anagnostopoulou e Izvorski (2003) e Pancheva (2003), apresentados na seção 1 deste artigo.

6. A descrição dos sujeitos inserida nesta seção sobre cada etapa metodológica busca explicitar o perfil dos sujeitos incluídos nesta pesquisa a fim de caracterizar detalhadamente o grupo de participantes do estudo. No entanto, o objetivo do estudo não é confrontar a produção de PE no inglês americano por sujeitos de faixas etárias diferentes.

7. A associação de tais advérbios aos verbos descritos foi motivada exclusivamente pela história apresentada no diálogo criado para o teste, de modo que o advérbio recently era favorecido nas sentenças com os verbos to take e to throw e o advérbio before, na sentença com o verbo to see. Assumimos que não haveria distinção na seleção da forma de passado simples ou composto em função do verbo elencado para figurar na lacuna-alvo.

8. Nos exemplos (8) e (9), foram incluídas uma glosa e uma possível tradução para sentenças selecionadas do teste. Por outro lado, aos participantes eram apresentadas as sentenças sem tais informações. Os diálogos, tais como apresentados aos participantes, podem ser verificados na íntegra no apêndice A.

9. O sinal de interrogação aplicado aqui justifica-se pelo fato de tal forma verbal ser morfologicamente ambígua, podendo ser tanto a forma de particípio, que justificaria a glosa como "ler.PTCP", quanto a forma de passado simples, que justificaria a glosa como "ler.PST".

10. Neste caso, a forma verbal utilizada pelo participante, descartada da análise, foi a seguinte: "I bumped (into) across Daniel as well, from high school!". Este verbo em particular é regular, e sua forma de passado simples e de particípio são iguais, dando origem à chamada "forma morfologicamente ambígua". Nas demais ocorrências descartadas, referenciadas nesta seção, tem-se produção semelhante a esse dado.

11. As traduções possíveis para os verbos, de acordo com o contexto em que foram inseridos, são: to come (across) (topar-se com), to take (fazer), to go (ir), to throw (dar; preparar), to undergo (through) (passar por), to see (ver). 
12. Respectivamente, as traduções para os exemplos retirados do corpus são: "Eles [os cavalos] não foram disciplinados/treinados o suficiente" e "Eu acabei de ler um artigo sobre ele".

13. Exemplos retirados de Molsing (2010, p. 1). Respectivamente, as traduções para as sentenças são: "John chegou atrasado uma vez" e "John chegou atrasado três vezes".

14. Agradece-se ao parecerista anônimo pela contribuição valiosa com essa possível interpretação para os dados obtidos.

15. A tradução para o exemplo em questão é: "John deu/preparou festas em casa recentemente".

\section{Referências}

ALEXIADOU, A.; RATHERT, M.; VON STECHOW, A. Introduction: the modules of Perfect constructions. In: ALEXIADOU, A.; RATHERT, M.; VON STECHOW, A. (eds.). Perfect Explorations. Berlin: Mouton de Gruyter, 2003. p. vii-xxxviii.

CINQUE, G. Adverbs and functional heads: a cross-linguistic perspective. New York: Oxford University Press, 1999.

COMRIE, B. Aspect: an introduction to the study of verbal aspect and related problems. New York: Cambridge University Press, 1976.

DOWTY, D. R. Word meaning and Montague grammar: The semantics of verbs and times in generative semantics and in Montague's PTQ. Dordrecht: D. Reidel Publishing Company, 1979.

FENN, P. A semantic and pragmatic examination of the English perfect. Berlin: Gunter Narr Verlag, 1987.

IATRIDOU, S.; ANAGNOSTOPOULOU, E.; IZVORSKI, R. Observations about the form and meaning of the perfect. In: ALEXIADOU, A.; RATHERT, M.; VON STECHOW, A. (eds.). Perfect Explorations. Berlin: Mouton de Gruyter, 2003. p. 153-205.

GUILFOYLE, E.; NOONAN, M. Functional categories and language acquisition. Canadian Journal of Linguistics/Revue Canadienne de Linguistique, v. 37, n. 2, p. 241-272, 1992.

ILARI, R.; OLIVEIRA, M. F.; BASSO, R. M. Tense and Aspect: A Survey. In: WETZELS, W. L.; COSTA, J.; MENUZZI, S. The Handbook of Portuguese Linguistics. Malden: Wiley Blackwell, 2016. p. 392-407.

JESUS, J. L. O aspecto perfect no inglês dos Estados Unidos (IEU) e no português do Brasil (PB): uma análise do perfect do tipo universal. In: 7a SIAC, 2016, Rio de Janeiro: UFRJ.

LOPES, T. L. A realização morfológica do aspecto perfect no português do Brasil e no inglês da Inglaterra: uma análise comparativa. Dissertação (Mestrado em Linguística) - Faculdade de Letras, UFRJ, Rio de Janeiro, 2016.

MOLSING, K. V. The Present Perfect: an exercise in the study of events, plurality and aspect. Tese (Doutorado em Letras) - Pontifícia Universidade Católica do Rio Grande do Sul, Porto Alegre, 2010.

NESPOLI, J. B. Representação mental do perfect e suas realizações nas línguas românicas: um estudo comparativo. Tese (Doutorado em Linguística) - Faculdade de Letras, UFRJ, Rio de Janeiro, 2018. 
NESPOLI, J. B.; MARTINS, A. L. A representação sintática do aspecto perfect: uma análise comparativa entre o português e o italiano. Cadernos de Estudos Linguísticos, Campinas, v. 60, n. 1, p. 30-46, 2018.

PANCHEVA, $R$. The aspectual makeup of perfect participles and the interpretations of the perfect. In: ALEXIADOU, A.; RATHERT, M.; VON STECHOW, A. (eds.). Perfect Explorations. Berlin: Mouton de Gruyter, 2003. p. 277-308.

RODRIGUES, N. Aquisição de perfect no português do Brasil. Dissertação (Mestrado em Linguística) - Faculdade de Letras, UFRJ, Rio de Janeiro, 2019.

RODRIGUES, N.; MARTINS, A. L.; NESPOLI, J. B. Aquisição de perfect no inglês americano. In: ABRALIN 50 ANOS, 2019, Maceió.

SMITH, C. The parameter of aspect. Dordrecht: Kluwer, 1997.

VERKUYL, H. On the compositional nature of the aspects. Dordrecht: D. Reidel Publishing Company, 1972.

Recebido em: 27/02/2020

Aceito em: 20/05/2020 


\section{APÊNDICE A - Diálogos criados para o teste de preenchimento de lacunas}

\section{Diálogo 1}

Dennis and Joanna are close friends, but they eventually lost contact. They are at the supermarket and, suddenly, they bump into each other.

Joanna: Whoops! I'm sorry, sir!

Dennis: It's OK... Joanna, is that you?

Joanna: Oh my God, Dennis! I can't believe it! Long time no see, right?

Dennis: Totally! How are you?

Joanna: I'm fine! Jesus, this is the day of coincidences! I (to come) across

Daniel as well, from high school! It was just NOW! Remember him?

Dennis: I do! He used to sit next to me in Algebra, so smart! Anyway, are you living here now in Los Angeles? I (to have) no idea!

Joanna: Actually, no! I'm just here now because of work.

Dennis: And do you know anything about LA?

Joanna: I know some places all right, but maybe you could show me around some more?

Dennis: Of course! And what is that job about?

Joanna: You know, I (to be) a journalist. I (to write) articles about music for a living, and I am here to develop an article about the local scene! Dennis: Cool! I (to take) a writing course recently, I loved it! Maybe you could check my texts to see if I have a chance of (to become) a pro... Joanna: Oh, glad to do so! Send me an e-mail! Dennis: All right! I'm so happy for you! Gotta go, but I hope we can catch up later. See ya! Joanna: See ya!

\section{Diálogo 2}

Peter and Chris are friends from college. During one of their lunch breaks, they chitchat about Beyoncé and Brazil, since Peter is passionate about both of them.

Peter: I wish I could go to a Beyoncés concert. I'm such a big fan! Chris: She's a great singer, right? I (to go) to one of her concerts, totally amazing!

Peter: No way! When was it?

Chris: It was last year, in Rio de Janeiro! I was on vacation and had the chance to go, so I (to take) it!

Peter: Can't believe it, I love Brazil! I (to throw) a Brazilian-themed party to celebrate my birthday recently. You see how obsessed I am with this country. 
Chris: I thought your party was gonna be all about Beyoncé!

Peter: I (to have) one like this last year, so I (to want) to change

themes.

Chris: (to make) sense! I wish I was there!

Peter: No problem, next year you'll be there!

Chris: I'm sure!

\section{Diálogo 3}

Morgan knows Anderson for ages and knows all about his romantic deals. However, she won't put up with him this time, when he is about to break some interesting news at a cocktail party.

Anderson: Gosh, my vacation was amazing! Wanna know about it? Morgan: Do I (to have) any other options?

Anderson: You know you don't! So, this vacation in fact was quite good, but I (to undergo) through some bad ones, right? You know that! That's why I need to share this with you.

Morgan: I (to understand), I was just joking, dear. Spill it out! Anderson: So, I went to New York and I believe I found the love of my life! Morgan: Really? Your vacation (to be) amazing not because you enjoyed the city or anything, but because you (to find) someone interesting there? Anderson: Could you pretend to be happy for me, at least? I (to see) so many cute and stupid guys before, but now I think I have found the right one... Morgan: I'm so happy for you, dear! I hope it will last THIS TIME. Anderson: Thank you! I'll make sure NOT to invite you to our wedding! Morgan: Love you, too! 